\title{
Antimicrobial resistance and molecular detection of extended spectrum $\beta$ - lactamase producing Escherichia coli isolates from raw meat in Greater Accra region, Ghana
}

Esther Dsani ${ }^{1,2}$, Edwin Andrews Afari ${ }^{1}$, Anthony Danso-Appiah ${ }^{1}$, Ernest Kenu ${ }^{1}$, Basil Benduri Kaburi ${ }^{1}$ and Beverly Egyir ${ }^{3^{*}}$ (D)

\begin{abstract}
Background: Typically, raw meat can be contaminated with antibiotic resistant pathogens at unhygienic slaughter and sale points. Consumption of meat contaminated with antibiotic resistant $E$. coli is associated with grave health care consequences. The aim of this study was to determine the microbial quality of raw meat, the antimicrobial susceptibility and Extended Spectrum Beta Lactamase (ESBL) production in E. coli isolates from raw meat.

Results: Total Plate Counts exceeded the acceptable limit of $5.0 \mathrm{log}$ CFU/ $\mathrm{cm}^{2}$ in $60.5 \%$ (124/205) of raw meat samples. Total Coliform Counts in 70.7\% (145/205) of samples were in excess of the acceptable limit of 2.5 log CFU/ $\mathrm{cm}^{2}$. E. coli was detected in about half of raw meat samples (48\%), ranging from 9.5-79.0\% among the slaughter sites. Isolates were susceptible to meropenem (100\%), ceftriaxone (99\%), cefotaxime (98\%), chloramphenicol (97\%), gentamycin (97\%), ciprofloxacin (92\%) and amikacin (92\%), but resistant to ampicillin (57\%), tetracycline (45\%), sulfamethoxazole-trimethoprim (21\%) and cefuroxime (17\%). Multi-drug resistance (MDR) was identified in 22\% of the isolates. The bla TEM gene was detected in $4 \%$ (4/98) of E. coli isolates in this study.

Conclusion: The levels of microbial contamination of raw meat in this study were unacceptable. Meat handlers and consumers are at risk of foodborne infections from E. coli including ESBL producing E. coli that are resistant to most antibiotics in use. We recommend an enhanced surveillance for antibiotic resistance in food products for the early detection of emerging resistant bacteria species in the food chain.
\end{abstract}

Keywords: Antibiotic resistance, E. coli, Raw meat, ESBL, Ghana

\footnotetext{
*Correspondence: beverly.egyir@gmail.com; begyir@noguchi.ug.edu.gh

${ }^{3}$ Bacteriology Department, Noguchi Memorial Institute for Medical Research, University of Ghana, Accra, Ghana
}

Full list of author information is available at the end of the article

C C The Author(s). 2020 Open Access This article is licensed under a Creative Commons Attribution 4.0 International License, which permits use, sharing, adaptation, distribution and reproduction in any medium or format, as long as you give appropriate credit to the original author(s) and the source, provide a link to the Creative Commons licence, and indicate if changes were made. The images or other third party material in this article are included in the article's Creative Commons licence, unless indicated otherwise in a credit line to the material. If material is not included in the article's Creative Commons licence and your intended use is not permitted by statutory regulation or exceeds the permitted use, you will need to obtain permission directly from the copyright holder. To view a copy of this licence, visit http://creativecommons.org/licenses/by/4.0/ The Creative Commons Public Domain Dedication waiver (http://creativecommons.org/publicdomain/zero/1.0/) applies to the data made available in this article, unless otherwise stated in a credit line to the data. 


\section{Background}

The emergence of antibiotic resistance in bacteria commonly found in food animals has garnered attention globally for its potential contribution to human colonization with antibiotic resistant bacteria. Antibiotics are used in food animals for therapeutic and nontherapeutic purposes. The continuous use of antibiotics in food animal production is cited as a major determinant for carriage of antibiotic resistant bacteria in food animals [1]. A proportion of antibiotic classes are used in both animals and humans, creating the need to monitor the spread of resistant bacteria from animals to humans at all stages of the transmission pathway [2].

Food products of animal origin contaminated with drug resistant bacteria may provide a direct route for human colonization [3]. Meat is an important part of the Ghanaian diet and is often sourced from open markets and cold stores. Chicken, beef and chevon are the most patronized meat types while pork and mutton have low patronage [4]. Although selective pressure due to antibiotic use in primary production is considered as a major source of antibiotic resistant bacteria in livestock products, sanitary conditions at slaughter, sale and processing points may affect the pattern and intensity of spread along the food chain [5, 6]. Escherichia coli is a common colonizer of the intestinal tract of humans and animals, and is widely known to cause bacteremia in humans [7]. The presence of pathogenic strains of E. coli in meat and dairy products has been associated with foodborne disease outbreaks in humans [8].

Extended spectrum beta lactamase (ESBL), an enzyme produced by some gram negative bacteria, poses a peculiar challenge for treatment as it confers resistance to penicillins, cephalosporins and monobactams [9]. Extended spectrum TEM-, SHV- and CTX-M type enzymes have been detected in Enterobacteriaceae from retail food [10]. ESBL-producing E. coli have been reported in patients with urinary tract infections worldwide [11]. The contribution of the food chain to the occurrence of ESBL bacteria in humans is widely debated with fecal-oral and nosocomial transmissions largely influencing its emergence and spread in humans [12]. Monitoring the trend of spread of ESBL positive $E$. coli through the food chain is necessary in settings where humans have routine contact with livestock and their products, because of the increased risk of spread of resistance genes in these interactions.

In Ghana, it has been found that, resistance in Enterobacteriaceae to commonly used antibiotic agents is widespread [13]. Research evidence on microbial contamination of meat and their antibiotic resistance patterns is limited and thus, it is difficult to assess the risk posed to human health through the food chain. Yet, such evidence is critical for guiding future antimicrobial therapy. The aim of this study was to determine the level of microbial contamination of raw meat, presence of $E$. coli and their resistance to commonly prescribed antibiotics for human infections. This study also detected the occurrence of ESBL production among E. coli isolates recovered from raw meat.

\section{Results \\ Microbial contamination of raw meat}

Overall, $124(60.5 \%)$ samples from raw meat in this study exceeded the maximum limit of $5.0 \log \mathrm{CFU} / \mathrm{cm}^{2}$, for total aerobic counts for cattle, sheep and goat carcasses set by the Ghana Standards Authority and the European Commission Regulation (EC) on the microbial criteria for food stuffs. Total Plate Counts for all 205 samples ranged from $2.86 \mathrm{log} \mathrm{CFU} / \mathrm{cm}^{2}$ to $7.26 \mathrm{log}$ $\mathrm{CFU} / \mathrm{cm}^{2}$ with a median of $5.28 \log \mathrm{CFU} / \mathrm{cm}^{2}$ (Table 1). More than half of all samples (70.7\%) had coliform counts exceeding the acceptable limit of $2.5 \log \mathrm{CFU} /$ $\mathrm{cm}^{2}$. Total coliform counts ranged from $0.11 \log$ CFU/ $\mathrm{cm}^{2}$ to $5.76 \log \mathrm{CFU} / \mathrm{cm}^{2}$ with a median of $3.12 \mathrm{log}$ $\mathrm{CFU} / \mathrm{cm}^{2}$ (Table 1). The Plate Count and Coliform Count distribution among the three slaughter sites is shown in Figs. 1 and 2. The Kruskal-Wallis test showed that there was a statistically significant difference in total plate counts between the three slaughter sites, $\chi^{2}(2)=$ 73.81, $p=0.0001$. The distribution of coliforms in samples from the three sites were also found to differ significantly, $\chi^{2}(2)=110.94, p=0.0001$.

\section{Contamination of raw meat with $E$. coli}

E. coli was detected in $48 \%(98 / 205)$ of all samples. The proportion of meat contaminated with $E$. coli was $79 \%$ $(50 / 63)$ at the public slaughterhouse, 53\% (42/79) at the slaughter slab and $9.5 \%(6 / 63)$ at the privately-owned slaughterhouse (Table 2). The rate of E. coli contamination was $61.7 \%(50 / 81)$ in samples obtained from beef, $40.7 \%(44 / 108)$ for chevon and $25 \%(4 / 16)$ for mutton. The results of the chi-square test showed that there was a significant difference in the proportions of $E$. coli contaminated meat among the slaughter sites $(p<0.05)$.

Table 1 Microbiological quality of raw meat samples from selected slaughterhouses in the Greater Accra region of Ghana

\begin{tabular}{|c|c|c|}
\hline \multirow[t]{2}{*}{ Slaughterhouse } & \multicolumn{2}{|c|}{ Median count in log CFU/cm² (range) } \\
\hline & Total Plate Count & Total Coliform Count \\
\hline PS & $5.33(4.92-5.65)$ & $3.12(2.42-3.92)$ \\
\hline SS & $6.15(3.15-6.87)$ & $4.05(1.52-5.76)$ \\
\hline PO & $3.57(2.86-7.26)$ & $0.84(0.11-5.54)$ \\
\hline Total (all sites) & $5.28(2.86-7.26)$ & $3.12(0.11-5.76)$ \\
\hline
\end{tabular}

PS Public slaughterhouse, SS Slaughter slab, $P O$ Privately-owned slaughterhouse 


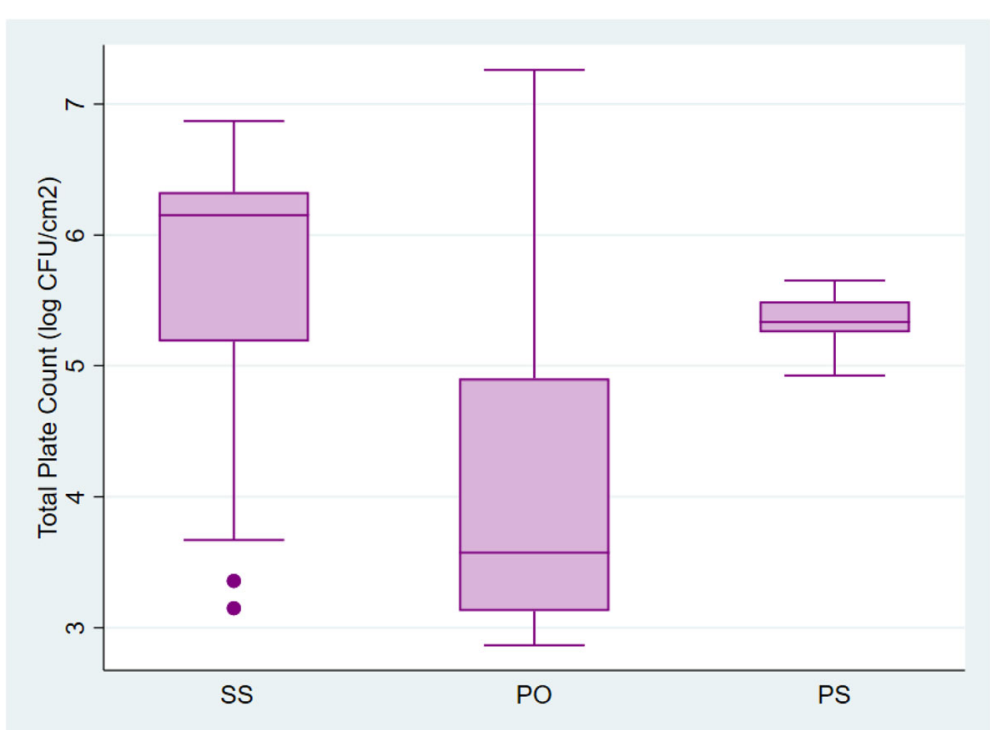

Fig. 1 Distribution of Total Plate Counts among the three slaughter sites. SS- Slaughter slab, PO- Privately-owned slaughterhouse, PSPublic slaughterhouse

\section{Antimicrobial susceptibility and detection of ESBL production}

E. coli isolates recovered were frequently resistant to ampicillin (57\%), tetracycline (45\%), cefuroxime (21\%), and sulphamethoxazole/trimethoprim (SXT) (17\%) (Table 3). High rates of susceptibility were observed for ceftriaxone (99\%), cefotaxime (98\%), chloramphenicol (97\%), gentamycin (97\%), ciprofloxacin (92\%) and amikacin (92\%) (Table 3). All isolates were susceptible to meropenem. Of the $98 E$. coli isolates tested, $84 \%(82 / 98)$ showed resistance to at least one out of the eleven antimicrobial agents. In all, 22\% $(22 / 98)$ of the isolates were multidrug resistant. Among the multidrug resistant E. coli, concurrent resistance to penicillin, tetracycline and SXT (32\%), was most common (Fig. 3). Other patterns observed were resistance to penicillin, tetracycline, SXT, and fluoroquinolone class of antibiotics (14\%), penicillin, tetracycline and cephalosporin class of antibiotics (14\%), penicillin, tetracycline and amphenicols $(10 \%)$ and penicillin, aminoglycoside, SXT, tetracycline and cephalosporin (10\%). Most of the MDR patterns observed

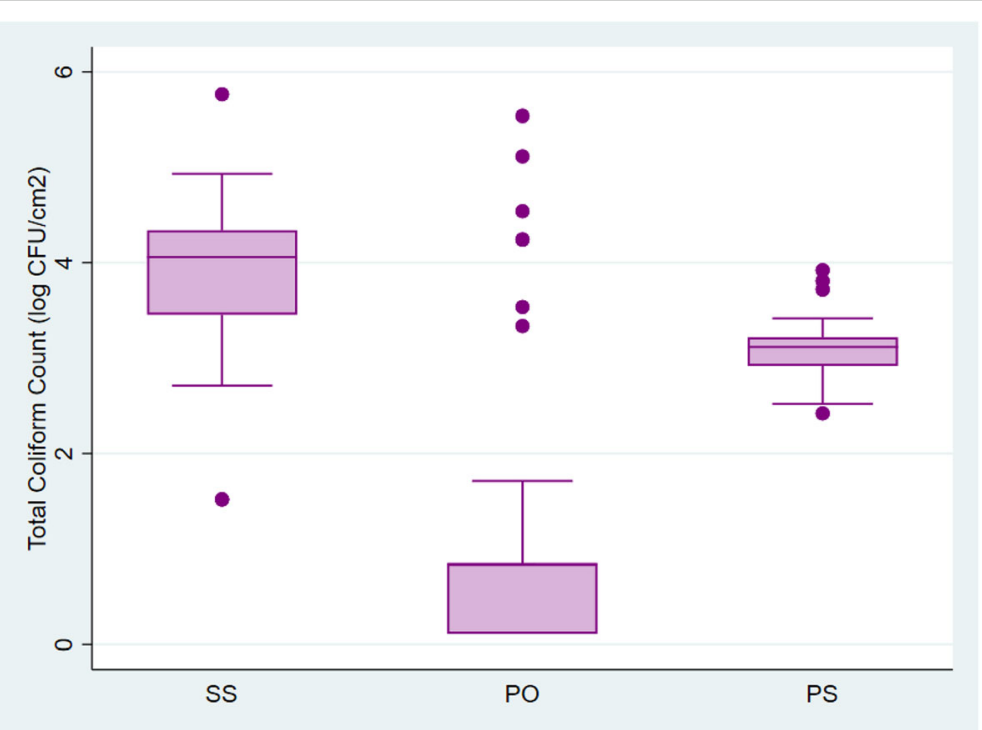

Fig. 2 Distribution of Total Coliform Counts among the three slaughter sites. SS- Slaughter slab, PO- Privately-owned slaughterhouse, PSPublic slaughterhouse 
Table 2 Distribution of E. coli isolated from meat at slaughterhouses

\begin{tabular}{|c|c|c|c|c|c|c|c|c|}
\hline \multirow{2}{*}{$\begin{array}{l}\text { Meat } \\
\text { type }\end{array}$} & \multicolumn{2}{|l|}{ PS } & \multicolumn{2}{|l|}{ SS } & \multicolumn{2}{|l|}{$\mathrm{PO}$} & \multicolumn{2}{|l|}{ Total } \\
\hline & Samples tested & E. coli positive & Samples tested & E. coli positive & Samples tested & E. coli positive & Samples tested & E. coli positive \\
\hline Beef & 54 & $42(78 \%)$ & 24 & $8(33 \%)$ & 3 & - & 81 & $50(61.7 \%)$ \\
\hline Mutton & - & - & 9 & $3(33 \%)$ & 7 & $1(14 \%)$ & 16 & $4(25.0 \%)$ \\
\hline Chevon & 9 & $8(89 \%)$ & 46 & 31 (67\%) & 53 & $5(9 \%)$ & 108 & $44(40.7 \%)$ \\
\hline Total & 63 & 50 (79\%) & 79 & $42(53 \%)$ & 63 & $6(9.5 \%)$ & 205 & $98(48.0 \%)$ \\
\hline
\end{tabular}

PS Public slaughterhouse, SS Slaughter slab, PO Privately-owned slaughterhouse

in the E. coli isolates (95\%) showed resistance to penicillin and tetracycline class of antibiotics in addition to other antimicrobial classes. Out of the $98 \mathrm{E}$. coli isolates recovered from raw meat, 14 isolates were presumed to be ESBL producers based on the results of the combination disk test. Out of these, four [4] E. coli isolates were found to have the $b a_{T E M}$ gene. Majority of E. coli isolates found to have the bla $a_{T E M}$ gene (3/4), showed phenotypic resistance to ampicillin, amikacin, tetracycline, SXT and cefuroxime. $B l a_{S H V}$, and $b l a_{C T X-M}$ genes were not detected in the isolates screened.

\section{Discussion}

The study findings show that, in most cases $(>60 \%)$, raw meat that are ready for sale at the selected study sites had microbial loads exceeding the acceptable limit. The majority of slaughtering in Ghana is conducted at slaughterhouses and slabs with sub-standard conditions of slaughter and minimal oversight from food safety authorities [14]. The absence of hygiene standards at points of slaughter has been linked to increased microbial contamination of carcasses [15]. High coliform and plate counts observed at the public slaughterhouse and slaughter slab may stem from the introduction of contaminants from floor surfaces, hides and faeces of livestock in the absence of standard operating procedures that ensure sanitary standards are met in the slaughter environment. Contamination of meat in such situations may also be exacerbated by inadequate slaughter infrastructure that ensures that work areas are properly segregated [16]. The consequence for human health lies in the potential exposure of consumers to disease causing organisms and carriage of drug resistant bacteria [17].

E. coli is commonly used as an indicator organism for assessing food and water hygiene [18]. Although E. coli was detected in close to half of raw meat sampled, wideranging proportions of $E$. coli contamination was observed at the slaughter sites (9.5-79\%). Previous studies on $E$. coli in beef from retail joints in Northern Ghana similarly reported wide- ranging values of $0-100 \%$ [19]. While high $E$. coli contamination rates often indicate poor slaughter hygiene, the presence of other environmental contaminants in heavily contaminated settings may reduce recovery rates of E. coli. Slaughter slabs have less adequate service modules in comparison to slaughterhouses in Ghana. Privately-owned slaughterhouses often have better slaughter infrastructure and compliance to hygienic practices in an effort to maintain customer satisfaction. This phenomenon may account for the low levels of E. coli contamination (9.5\%) observed for the Privately-owned slaughterhouse.

Table 3 Antimicrobial resistance profile of E. coli isolates from raw meat at the selected slaughter sites in the Greater Accra region of Ghana

\begin{tabular}{|c|c|c|c|c|}
\hline Antimicrobial agent & $\begin{array}{l}\text { PS } \\
n=50(\%)\end{array}$ & $\begin{array}{l}\text { SS } \\
n=42,(\%)\end{array}$ & $\begin{array}{l}\mathrm{PO} \\
n=6(\%)\end{array}$ & $\begin{array}{l}\text { Total } \\
N=98,(\%)\end{array}$ \\
\hline Ampicillin & $23(46)$ & $33(79)$ & $0(0)$ & $56(57)$ \\
\hline Tetracycline & $26(52)$ & $18(43)$ & $0(0)$ & $44(45)$ \\
\hline Cefuroxime & $8(16)$ & $13(30)$ & $0(0)$ & $21(21)$ \\
\hline Sulphamethoxazole/Trimethoprim & $10(20)$ & $7(16)$ & $0(0)$ & $17(17)$ \\
\hline Amikacin & $2(4)$ & $6(14)$ & $0(0)$ & $8(8)$ \\
\hline Ciprofloxacin & $4(8)$ & $3(7)$ & $1(16)$ & $8(8)$ \\
\hline Cefotaxime & $1(2)$ & $1(2)$ & $0(0)$ & $2(2.1)$ \\
\hline Gentamycin & $2(4)$ & $1(2)$ & $0(0)$ & $3(3.1)$ \\
\hline Chloramphenicol & $2(4)$ & $1(2)$ & $0(0)$ & $3(3.1)$ \\
\hline Ceftriaxone & $0(0)$ & $1(2)$ & $0(0)$ & $1(1)$ \\
\hline Meropenem & $0(0)$ & $0(0)$ & $0(0)$ & $0(0)$ \\
\hline
\end{tabular}

$n$ Number of E. coli isolates, PS Public slaughterhouse, SS Slaughter slab, PO Privately-owned slaughterhouse 


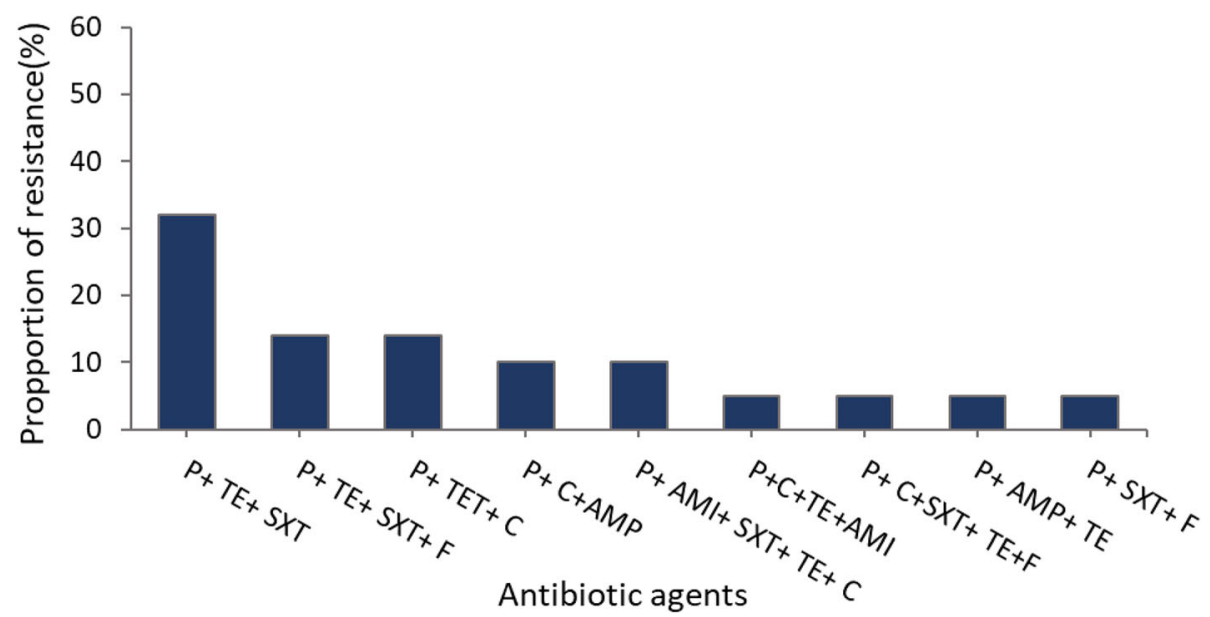

Fig. 3 Multidrug resistance profiles of E. coli isolates. P-Penicillin, TE- Tetracycline, SXT-Sulphamethoxazole/ Trimethoprim, AMI- Aminoglycoside, CCephalosporin, F-Quinolones/Fluoroquinolones, AMP-Amphenicol

The highest rate of resistance in E. coli was observed for ampicillin (57\%). This follows a commonly reported pattern of beta- lactam antibiotic resistance rates of more than $50 \%$ in foods of animal origin [20, 21]. While these observations were attributed to the common use of ampicillin and penicillin derivatives in food animals, the scale of resistance is largely dependent on the food animal type and route of administration [22]. Subtherapeutic doses of beta-lactams administered through feed and water in poultry and the pig industry may yield higher rates of resistance than in cattle where parenteral administration is common [23]. The levels of resistance to tetracycline (45\%) and SXT (17\%) observed in this study have similarly been reported in E. coli from beef in Ghana (44 and 18\%) [24]. Tetracyclines are commonly used for therapy in humans and livestock and for growth promotion in intensive farming systems through feed [25]. High transferability of tetracycline resistance determinants in gut bacteria of livestock in such settings may contribute to the observed rates of tetracycline resistance in $E$. coli isolated from raw meat, meat products and the environment [26].

We documented lower rates of resistance of $E$. coli to cefuroxime in comparison to isolates recovered from clinical specimens in Ghana [27]. In comparison to its use in humans, second generation cephalosporins are less commonly used in food animals and are broadly approved for the treatment of mastitis in dairy cattle [28]. Among SXT resistant E. coli isolates of animal origin, ampicillin and tetracycline have been identified in previous studies as common cotransferred resistant phenotypes [29]. The MDR rate of $22 \%$ in E. coli isolates was similar to studies carried out by Saud et al. on raw buffalo meat while significantly higher rates were observed for chicken in the same study [30]. These findings can be attributed to the routine use of antibiotics in poultry feed and less common use of oral antibiotics in large animals. The detection of the TEM gene in four E. coli isolates is comparable to studies by Sheikh et al. that found a lower incidence of the TEM gene in ground beef as compared to other meat types [31]. Several factors may account for the low proportion of ESBL producing E. coli recovered in this study. Studies conducted by Aldeyab et al. posited that community incidence of ESBL-producing bacteria was significantly linked to amoxicillin-clavulanic acid use while hospital incidence was linked to fluoroquinolone use in health care settings [32]. ESBL production in Enterobacteriaceae recovered from foods of animal origin may reflect the burden of resistance to certain classes of antimicrobial drugs in gut bacteria in different food animals. The presence of ESBL-producing E. coli in raw meat may cause infections in humans and lead to prolonged hospital stays, increased medical costs, increased mortality and morbidity [33].

Our isolates showed high susceptibility rates to meropenem, ceftriaxone, chloramphenicol, and gentamycin. Third generation cephalosporins and phenicols are not commonly used in livestock in Ghana, thus their efficacy has been maintained [34]. Preserving the efficacy of these drugs is a necessary measure as they fall in the category of critically needed antibiotics used to treat lifethreatening infections caused by $E$. coli in humans.

While this study provides evidence of the presence of drug resistant bacteria in raw meat, its interpretation is limited to known determinants of resistance in the primary production chain as environmental determinants such as water and soil were not assessed. Water used in the slaughter process may serve as a reservoir of 
antibiotic resistant bacteria and a constant source of contamination for raw meat. The study did not assess the contribution of soil microbiome at the study sites to contamination of raw meat with antibiotic resistant bacteria. Future studies that provide a holistic approach for determining the sources of raw meat contamination at slaughter sites are required to reduce the risk of spread of antibiotic resistant bacteria to humans through the food chain.

\section{Conclusions}

Our study found that more than half of meat samples had unacceptable levels of microbial contamination. Contamination with E. coli was found in $48 \%$ of meat samples with multidrug resistance observed in $22 \%$ of isolates. Meat handlers at the selected slaughter sites and consumers are at risk of foodborne infections from E. coli including ESBL producing E. coli that are resistant at various levels to most antibiotics in use. This calls for further investigation of the sources of meat contamination and an assessment of hygiene standards in slaughterhouses in the Greater Accra Region. Control of potential hazards at slaughter is a necessary measure to minimize the incidence of contamination in meat. Enhanced surveillance in food products of animal origin is required to monitor trends in resistance patterns and promptly detect emerging resistant bacteria.

\section{Methods}

\section{Study sites and sample collection}

A cross-sectional study involving the collection of surface swab samples from meat was conducted at three slaughter sites in the Greater Accra region of Ghana from January 2019 to June 2019. The sites consisted of a public slaughterhouse, a slaughter slab and a privately-owned slaughterhouse. Cattle and goats were slaughtered daily at all three sites whereas sheep were slaughtered occasionally. Butchers operating at these slaughter sites obtained their livestock mainly from the three northern regions of Ghana. All three sites were points of meat sale and had the basic modules of production, which included a slaughter floor and lairage/holding pen. All parts of carcasses were sold as meat in large cuts and small cuts at these sites. On predetermined weekly sampling days, a random number was generated for the first sample after which systematic random sampling was used for the selection of up to 5 carcasses for each meat type. A total of 205 surface swab samples were collected from beef $(n=81)$, chevon $(n=108)$ and mutton $(n=16)$. Sample collection was done immediately after carcass dressing with a sterile cotton swab and a sterile template of size $100 \mathrm{~cm}^{2}$ for cattle and $25 \mathrm{~cm}^{2}$ for goat and sheep carcasses. For each beef carcass, surface swabs were collected from the thigh, brisket and flank and pooled into a single tube containing $10 \mathrm{ml}$ of Buffered Peptone Water (BPW). Swabs from goat and sheep carcasses were obtained from thigh, brisket and mid-loin [35]. All samples were transported to the Bacteriology Department, Noguchi Memorial Institute for Medical Research, within $2 \mathrm{~h}$ of sample collection for processing.

\section{Enumeration of bacteria}

Total plate counts and total coliform counts were performed for all samples using the pour plate method. Serial dilutions of ten-fold units of each sample were plated on Plate Count Agar (Oxoid) and incubated for $48 \mathrm{~h}$ at $30^{\circ} \mathrm{C}$. Following incubation, plates with colonies ranging from 30 to 300 were counted and expressed in $\mathrm{CFU} / \mathrm{cm}^{2}$. The total coliform count was performed in the same way using Brilliance $E$. coli/ Coliform selective agar (Oxoid). The results of both counts were interpreted using guidelines set by the Ghana Standards Authority and the European Commission Regulation on the microbial criteria for food stuffs [36, 37]. Limits to total coliform counts were not specified in these documents hence limits set for Enterobacteriaceae counts in both documents were adopted for total coliform counts.

\section{Identification of $E$. coli in meat}

To isolate E. coli, samples were pre-enriched in Brain Heart Infusion (BHI) at $37^{\circ} \mathrm{C}$ for a period of $24 \mathrm{~h}$. Ten $(10 \mu \mathrm{l})$ microliters of each sample were then plated on MacConkey agar and incubated overnight at $37^{\circ} \mathrm{C}$. We identified E. coli by colony morphology and confirmed the isolates using Matrix Assisted Laser Desorption/Ionization -Time of Flight Mass Spectrometry (MALDI-TOF MS). Colonies from fresh overnight cultures were spotted on the MALDI-TOF MS target plate. One [1] $\mu \mathrm{l}$ of formic acid was then added and allowed to dry for $15 \mathrm{~min}$. One [1] $\mu \mathrm{l}$ of matrix preparation was placed on each sample and left to dry for a further $15 \mathrm{~min}$. MALDI-TOF MS was then conducted and ionization peaks (spectra) generated were matched against the integrated reference library of the MALDI system for confirmation of species of bacteria.

\section{Antimicrobial susceptibility testing}

Antimicrobial susceptibility testing was done by the Kirby Bauer disk diffusion method using the following antimicrobial agents (Oxoid Ltd., Hampshire, UK): ampicillin $(10 \mu \mathrm{g})$, tetracycline $(30 \mu \mathrm{g})$, cefuroxime $(30 \mu \mathrm{g})$, cefotaxime $(5 \mu \mathrm{g})$, ceftriaxone $(30 \mu \mathrm{g})$, amikacin 
Table 4 Oligonucleotide primers used to detect ESBL genes in E. coli isolates

\begin{tabular}{lll}
\hline Genes & Primer sequences & Expected amplicon size (bp) \\
\hline TEM-1 & Forward: 5'-GAGACAATAACCCTGGTAAAT-3' & 459 \\
& Reverse: 5'-AGAAGTAAGTTGCAGCAGTG-3' & 560 \\
CTX-M & Forward: 5'-GAAGGTCATCAAGAAGGTGCG-3' & 383 \\
& Reverse: 5'-GCATTGCACGCTTTCATAG-3' & 380 \\
SHV & Forward: 5'-GTCAGCGAAAAACACCTTGCC' & \\
& Reverse: 5'-GTCTATCGGCGATAAACCAG-3' & \\
\hline
\end{tabular}

$(30 \mu \mathrm{g})$, gentamycin $(10 \mu \mathrm{g})$, chloramphenicol $(30 \mu \mathrm{g})$, ciprofloxacin $(5 \mu \mathrm{g})$, sulphamethoxazole-trimethoprim $(25 \mu \mathrm{g})$ and meropenem $(10 \mu \mathrm{g})$. The procedure consisted of the preparation of a standard inoculum $(0.5$ McFarland) and inoculation on Mueller Hinton (MH) agar plates for $18 \mathrm{~h}$ at $35^{\circ} \mathrm{C}$ [38]. Interpretation of zone sizes was done using the EUCAST guideline [39]. E. coli ATCC 25922 was used to monitor the performance of the test. In this study, we defined multidrug resistance (MDR) as resistance to three or more classes of antimicrobial agents.

\section{Phenotypic and genotypic detection of ESBL production} The combination disk method was used to identify ESBL producing E. coli. Briefly, ceftazidime disks and ceftazidime combined with clavulanic acid disks were positioned $30 \mathrm{~mm}$ apart on the inoculated plates, and incubated overnight at a temperature of $37^{\circ} \mathrm{C}$. Isolates were classified as ESBL positive if the difference between the inhibition zone diameter of ceftazidime combined with clavulanic acid and diameter of the inhibition zone for the ceftazidime-only disk was $\geq 5 \mathrm{~mm}$ [40]. Cefotaxime disks and cefotaxime combined with clavulanic acid disks were used concurrently with ceftazidime for confirmation of ESBL production. DNA was extracted from presumptive colonies for the genotypic detection of ESBL production.

Bacterial DNA extraction consisted of placing pure colonies of overnight growth in $1 \mathrm{ml}$ of distilled water. The mixture was boiled for $10 \mathrm{~min}$ and centrifuged for $5 \mathrm{~min}$, at 1000 rotations per minute. Using the supernatant as a DNA template, PCR was done to detect ESBL resistance genes $\left(b l a_{T E M}, b l a_{S H V}\right.$, and $\left.b l a_{C T X-M}\right)$. The final volume of $25 \mu \mathrm{l}$ contained $2 \mu \mathrm{l}$ DNA template, $10 \mathrm{mM}$ of each primer (Table 4) [41], PCR grade water (10ul) and multiplex PCR master mix (13ul) (QIAGEN). Multiplex PCR was carried out in a thermal cycler with the following cycling conditions: $95^{\circ} \mathrm{C}$ for $5 \mathrm{~min}, 35$ cycles of $95^{\circ} \mathrm{C}$ for $30 \mathrm{~s}$, $60{ }^{\circ} \mathrm{C}$ for $30 \mathrm{~s}, 72^{\circ} \mathrm{C}$ for $2 \mathrm{~min}$, and a final extension lap at $72{ }^{\circ} \mathrm{C}$ for $10 \mathrm{~min}$.

\section{Statistical analysis}

Descriptive statistics were performed on carriage rates of $E$. coli and their resistance patterns. The
Chi-square test was used to assess differences in the proportion of $E$.coli detected in raw meat between the three slaughter sites. A Kruskal-Wallis test was performed to determine if there were significant differences in microbial counts in raw meat among the slaughter sites. Statistical analyses were performed at 95\% confidence level using STATA version 15.0.

\section{Abbreviations \\ ATCC: American type culture collection; CFU: Colony forming unit; EUCAST: European Committee on Antimicrobial Susceptibility Testing; ESBL: Extended spectrum beta lactamase; SXT: Sulphamethoxazole/ trimethoprim; MDR: Multi-drug resistance}

\section{Acknowledgements}

The authors are grateful to the slaughterhouse workers for their cooperation. The authors acknowledge the staff of the Bacteriology Department, Noguchi Memorial Institute for Medical Research, University of Ghana, the Veterinary Services Directorate of the Ministry of Food and Agriculture, and the School of Public Health, University of Ghana for their technical assistance throughout the study period.

\section{Authors' contributions}

ED and BE were involved in the design, acquisition of data, statistical analysis, interpretation of data and drafting of the manuscript. BE, EAA and ADA supervised the project work. EK and BBK contributed to data analysis and interpretation. All authors contributed to the writing of the manuscript and approved the final manuscript.

\section{Funding}

None to declare.

\section{Availability of data and materials}

The data sets used during the current study are available from the corresponding author on reasonable request.

\section{Ethics approval and consent to participate}

This study formed part of a thesis for a Master of Philosophy (MPhil) degree in Applied Epidemiology and Disease Control, and was approved by the Department of Epidemiology and Disease Control at the School of Public Health, University of Ghana. Sample collection was carried out with consent from butchers and livestock owners present at slaughter after permission was obtained from slaughterhouse authorities.

Consent for publication

Not applicable.

\section{Competing interests}

The authors declare that they have no competing interests.

\section{Author details}

${ }^{1}$ Department of Epidemiology and Disease Control, School of Public Health, University of Ghana, Accra, Ghana. ${ }^{2}$ Veterinary Services Directorate of the Ministry of Food and Agriculture, Accra, Ghana. ${ }^{3}$ Bacteriology Department, Noguchi Memorial Institute for Medical Research, University of Ghana, Accra, Ghana. 
Received: 20 May 2020 Accepted: 4 August 2020

Published online: 14 August 2020

\section{References}

1. Wall BA, Mateus ALP, Marshall L, Pfeiffer DU, Lubroth J, Ormel HJ, et al. Drivers, dynamics and epidemiology of antimicrobial resistance in animal production. Food and Agriculture Organization of the United Nations; 2016.

2. Martin MJ, Thottathil SE, Newman TB. Antibiotics overuse in animal agriculture: a call to action for health care providers. American Public Health Association; 2015.

3. Doyle ME. Multidrug-resistant pathogens in the food supply. Foodborne Pathog Dis. 2015;12(4):261-79.

4. Nkegbe EK, Assuming-Bediako N, Aikins-Wilson S, Hagan A. Meat consumption trends in some selected households in Accra Ghana. Asian J Agric Food Sci. 2013;1:4.

5. Witte W. Selective pressure by antibiotic use in livestock. Int J Antimicrob Agents. 2000;16:19-24.

6. Lerma LL, Benomar N, Knapp CW, Galeote DC, Gálvez A, Abriouel H. Diversity, distribution and quantification of antibiotic resistance genes in goat and lamb slaughterhouse surfaces and meat products. PLoS One. 2014;9:12

7. Makvana S, Krilov LR. Escherichia coli Infections. Pediatr Rev. 2015;36(4):167 LP-171.

8. Yang S-C, Lin C-H, Aljuffali IA, Fang J-Y. Current pathogenic Escherichia coli foodborne outbreak cases and therapy development. Arch Microbiol. 2017; 199(6):811-25.

9. Sah SK, Hemalatha S. Extended spectrum Beta lactamase (ESBL) mechanism of antibiotic resistance and epidemiology. Int J pharmtech Res. 2015;7(2): 303-9.

10. Ye Q, Wu Q, Zhang S, Zhang J, Yang G, Wang J, et al. Characterization of extended-spectrum $\beta$-lactamase-producing Enterobacteriaceae from retail food in China. Front Microbiol. 2018;9:1709.

11. Stadler T, Meinel D, Aguilar-Bultet $L$, Huisman JS, Schindler R, Egli A, et al. Transmission of ESBL-producing Enterobacteriaceae and their mobile genetic elements - identification of sources by whole genome sequencing: study protocol for an observational study in Switzerland. BMJ Open. 2018; 8(2):1-6.

12. Day MJ, Hopkins KL, Wareham DW, Toleman MA, Elviss N, Randall L, et al. Extended-spectrum $\beta$-lactamase-producing Escherichia coli in humanderived and foodchain-derived samples from England, Wales, and Scotland: an epidemiological surveillance and typing study. Lancet Infect Dis. 2019; 19(12):1325-35.

13. Opintan JA, Newman MJ, Arhin RE, Donkor ES, Gyansa-Lutterodt M, MillsPappoe W. Laboratory-based nationwide surveillance of antimicrobial resistance in Ghana. Infect Drug Resist. 2015;8:379.

14. Diop B, Daborn C, Schneider H. PVS gap analysis report: Ghana, 8-16 august, 2011. Paris: World Organ Anim Heal; 2012.

15. Bersisa A, Tulu D, Negera C. Investigation of bacteriological quality of meat from abattoir and butcher shops in Bishoftu, Central Ethiopia. Int J Microbiol. 2019

16. Cook EAJ, de Glanville WA, Thomas LF, Kariuki S, de Clare Bronsvoort BM, Fèvre EM. Working conditions and public health risks in slaughterhouses in western Kenya. BMC Public Health. 2017;17(1):14.

17. Organization $\mathbf{W H}$. Exposure assessment of microbiological hazards in food: guidelines. Vol. 7. World health Organization; 2008.

18. Centre for Food Safety, Food and Environmental Hygiene Department HK. Microbiological Guidelines for Food, 2014. https://www.cfs.gov.hk/english/ food_leg/files/food_leg_Microbiological_Guidelines_for_Food_e.pdf.

19. Adzitey F. Prevalence of Escherichia coli and Salmonella spp . in Beef Samples Sold at Tamale Metropolis, Ghana. Int J Meat Sci. 2015;5(1):8-13.

20. Altalhi AD, Gherbawy YA, Hassan SA. Antibiotic resistance in Escherichia coli isolated from retail raw chicken meat in Taif, Saudi Arabia. Foodborne Pathog Dis. 2010;7(3):281-5.

21. Trongjit S, Angkittitrakul S, Chuanchuen R. Occurrence and molecular characteristics of antimicrobial resistance of Escherichia coli from broilers, pigs and meat products in Thailand and Cambodia provinces. Microbiol Immunol. 2016;60(9):575-85.

22. Zhang L, Huang Y, Zhou Y, Buckley T, Wang HH. Antibiotic administration routes significantly influence the levels of antibiotic resistance in gut microbiota. Antimicrob Agents Chemother. 2013;57(8):3659-66.
23. Yassin AK, Gong J, Kelly P, Lu G, Guardabassi L, Wei L, et al. Antimicrobial resistance in clinical Escherichia coli isolates from poultry and livestock, China. PLoS One. 2017;12(9):e0185326.

24. Adzitey F. Antibiotic resistance of Escherichia coli isolated from beef and its related samples in Techiman municipality of Ghana. Asian J Anim Sci. 2015; 9(5):233-40.

25. Palmieri B, Di Cerbo A, Laurino C. Antibiotic treatments in zootechnology and effects induced on the food chain of domestic species and, comparatively, the human specie. Nutr Hosp. 2014;29(6):1427-33.

26. Shin SW, Shin MK, Jung M, Belaynehe KM, Yoo HS. Prevalence of antimicrobial resistance and transfer of tetracycline resistance genes in Escherichia coli isolates from beef cattle. Appl Environ Microbiol. 2015; 81(16):5560-6.

27. Forson AO, Tsidi WB, Nana-Adjei D, Quarchie MN, Obeng-Nkrumah N. Escherichia coli bacteriuria in pregnant women in Ghana: antibiotic resistance patterns and virulence factors. BMC Res Notes. 2018;11(1):901.

28. Hornish RE, Katarski SF. Cephalosporins in Veterinary Medicine - Ceftiofur Use in Food Animals. Vol. 2, Current Topics in Medicinal Chemistry; 2002. p. 717-31.

29. Tadesse DA, Zhao S, Tong E, Ayers S, Singh A, Bartholomew MJ, et al. Antimicrobial drug resistance in Escherichia coli from humans and food animals, United States, 1950-2002. Emerg Infect Dis. 2012;18(5):741.

30. Saud B, Paudel G, Khichaju S, Bajracharya D, Dhungana G, Awasthi MS, et al. Multidrug-resistant bacteria from raw meat of buffalo and chicken, Nepal. Vet Med Int. 2019

31. Sheikh AA, Checkley S, Avery B, Chalmers G, Bohaychuk V, Boerlin P, et al. Antimicrobial resistance and resistance genes in Escherichia coli isolated from retail meat purchased in Alberta, Canada. Foodborne Pathog Dis. 2012 9(7):625-31.

32. Aldeyab M. The impact of antibiotic use on the incidence and resistance pattern of extended-Spectrum Beta-lactamase-producing Bacteria in primary and secondary healthcare settings. Br J Clin Pharmacol. 2012.

33. Lee SY, Kotapati S, Kuti JL, Nightingale CH, Nicolau DP. Impact of extendedspectrum $\beta$-lactamase-producing Escherichia coli and Klebsiella species on clinical outcomes and hospital costs: a matched cohort study. Infect Contro Hosp Epidemiol. 2006;27(11):1226-32.

34. Sekyere JO. Antibiotic types and handling practices in disease management among pig farms in Ashanti region, Ghana. J Vet Med,2014.

35. Australian Government Department of Agriculture and Water Resources. Microbiological Manual for Sampling and Testing of Export Meat and Meat Products. 2018. https://www.agriculture.gov.au/export/controlled-goods/ meat/elmer-3/microbiological-manual.

36. Ghana Standards Authority. Standards Catalogue :GS ISO 4833-1. 2014

37. Commission Regulation (EC) No 2073/2005 of 15 November 2005 on microbiological criteria for foodstuffs. Off J Eur Union. 2005;338:1-26. https://eur-lex.europa.eu/legal-content/EN/ALL/?uri=CELEX\%3A32005R2073.

38. Zimbro JM, Power DA, Miller SM. Difco and BBL Manual of Microbial Culture Media. Second Edi; 2009. 686

39. European Committee on Antimicrobial Susceptibility Testing. Breakpoint tables for interpretation of MICs and zone diameters. Version 2018; https:// www.eucast.org/clinical_breakpoints/.

40. EUCAST guidelines for detection of resistance mechanisms and specific resistances of clinical and/or epidemiological importance. EUCAST, 2013.

41. Sharma M, Pathak S, Srivastava P. Prevalence and antibiogram of extended Spectrum $\beta$-lactamase (ESBL) producing gram negative bacilli and further molecular characterization of ESBL producing Escherichia coli and Klebsiella spp. J Clin diagnostic Res JCDR. 2013;7(10):2173.

\section{Publisher's Note}

Springer Nature remains neutral with regard to jurisdictional claims in published maps and institutional affiliations. 